\title{
TECHNOLOGY-MEDIATED LEARNING IN PHYSIOTHERAPY EDUCATION: THE SOCIAL CONSTRUCTION OF PRACTICE KNOWLEDGE
}

\begin{abstract}
Clinical practice is complex, requiring practitioners to interpret a diverse range of inter-related variables in order to make clinical decisions as part of patient management. This process is often intuitive and therefore hidden from students and less experienced clinicians, making the cognitive processes that inform clinical decision-making difficult to learn. In addition, educators still emphasise the learning of knowledge and skills through didactic teaching methods, such as lectures, in which students are passive "recipients" of knowledge. Unless physiotherapy educators design activities that aim to induct students into the professional culture and help them to develop ways of thinking and being that go beyond knowledge and skills, our students will continue to struggle with clinical reasoning.

In this position paper, we argue that the careful integration of technology as an adjunct to traditional lectures can be used to facilitate discussion and interaction as a way of developing practice knowledge in students. This leads to higher cognitive functioning as it provides the means by which learners construct their own personally meaningful understanding of the world through interaction with others. The promise of technology in physiotherapy education lies in its ability to create transformative learning experiences through enhanced communication that is mediated by more experienced teachers or peers. If technology is used to enhance the learning environment by providing richer and more meaningful platforms for communication and discussion, it may have a role to play in the social construction of knowledge as part of contextualised learning spaces.
\end{abstract}

KEY WORDS: PHYSIOTHERAPY, EDUCATION, BLENDED LEARNING, SITUATED COGNITION, COMMUNICATION, PRACTICE KNOWLEDGE

\section{INTRODUCTION}

Clinical practice is complex, partly because practitioners must review and re-prioritise patient problems in a process of active interpretation and the management of multiple dynamic and inter-related variables (Higgs, Richardson and Dahlgren 2004). By constantly reviewing the patient's con-

\section{Correspondence Author:}

\section{Prof JM Frantz}

Department of Physiotherapy

University of the Western Cape

Private Bag x17

Bellville 7530

South Africa

Email: jfrantz@uwc.ac.za, mrowe@uwc.ac.za dition, the healthcare professional must make decisions about how to proceed, taking into account the patient's response to a variety of interventions. Practice knowledge is therefore a relationship between questions and answers in a context that is often intuitive and hidden, especially from the novice practitioner (Higgs, Richardson and Dahlgren 2004). For this reason, an effective healthcare professional is not necessarily the one who knows all the facts but rather is someone who can access relevant knowledge efficiently when necessary, and who can form conceptual relationships between seemingly unrelated areas (Fraser and Greenhalgh 2001). Physiotherapy educators must therefore help students develop a process of reasoning that will allow them to make good clinical decisions in dynamic and complex environments.

Even though the past few decades have seen a change in our understanding of how learning happens, healthcare educators continue to emphasise the transmission of content in lectures as their preferred method of teaching (Graffam 2007). One of the main reasons that lectures are ineffective when it comes to changing students' ways of thinking is that information usually flows in one direction, from the lecturer to the class. This does not easily allow for the discussion that we know is important for learning (Laurillard 2012). While some lecturers will argue that they regularly ask questions and give students the opportunity to ask questions, students are often not asked 
to articulate their thinking, which makes it difficult for the teacher to address the errors in their understanding (Laurillard 2012). Lectures also presume that all students are at the same level and that the information being delivered is equally relevant for everyone. Lectures therefore do not always create authentic learning spaces since students are not required to engage with ideas, simply to "receive" them (Cohen 2004). If "teaching is about moving minds" to develop independent thinkers who will not bend to the will of teachers (Laurillard 2012 p. 5), then the predominant method of teaching in the healthcare professions should change.

If lectures are not effective for developing higher order cognitive skills like clinical reasoning and problemsolving, then what is? The aim of this paper is to argue that the lecture as a method of teaching in physiotherapy education may not lead to the effective development of the higher order thinking patterns that are necessary for effective clinical practice. Instead, we suggest that the integration of technology into the classroom be used as an adjunct to traditional lectures to facilitate discussion and interaction as a means of developing practice knowledge.

\section{KNOWLEDGE AS A SET OF TOOLS}

A common assumption made by many educators is that knowledge is separate from context and that it is a "substance" that can be transferred between people (Seely-Brown, Collins and Duguid 1989). Situated cognition positions learning as a situated activity in which knowledge construction must take place in the same context in which it will be used (Lave and Wenger 1991). When knowledge and context are separated, as is the case in most lectures, knowledge is seen as a product of learning, rather than a set of tools that can be used to solve problems (Herrington and Oliver 2000). Physiotherapy education can be thought of as a community where novice practitioners are introduced to the tools (i.e. the knowledge, skills and attitudes) that are necessary for them to participate effectively in the community. This enculturation into the community is achieved by creating opportunities for students to engage in authentic activities that require them to use the tools in order to solve contextually relevant problems within the community (Seely-Brown, Collins and Duguid 1989).

Discussion is an essential aspect of the process of enculturation that happens during the process of developing practice knowledge and clinical reasoning (Higgs, Richardson and Dahlgren 2004). This form of communication enables a social construction of knowledge that is mediated by a More Knowledgeable Other (MKO), who works in a collaborative partnership with students in order to help them achieve deeper understanding (Vygotsky 1978). This social construction of knowledge is dependent on language and symbols as a means of communicating abstract ideas through discussion. Structured communication therefore enables students to make conceptual leaps to higher cognitive levels, without which they would be unable to discern abstract knowledge (Laurillard 2002). Communication and discussion is therefore an essential aspect of the kind of learning that leads to higher cognitive function as it provides the means by which learners construct their own personally meaningful understanding of the world. It should be clear that contextual learning in which dialogue plays a major role would be difficult to incorporate into didactic teaching methods like lectures, with their emphasis on the one way transmission of content (Herrington 2006).

Physiotherapy educators should therefore aim to create authentic learning spaces where students can be introduced to, and immersed in, the culture of the profession, giving them the feeling of what it is like to be legitimate peripheral participants in a community of practice (Lombardi and Oblinger 2007). One way in which these kinds of learning spaces can be created is through the careful and intentional use of technology as part of the learning environment.

\section{EFFECTIVE USE OF TECHNOLOGY IN THE CLASSROOM}

The promise of technology in physiotherapy education lies in its ability to create transformative learning experiences through enhanced communication (Veletsianos 2011). This is an important consideration when viewed alongside Vygotsky's notion of the social construction of knowledge that is mediated by more experienced teachers or peers. This process is dependent on structured communication as a means of communicating abstract ideas through discussion, which enables learners to make conceptual leaps to higher cognitive levels (Vygotsky 1978). If technology is used to enhance the learning environment by providing richer and more meaningful platforms for communication and discussion, it may have a role to play in the social construction of knowledge as part of contextualised learning spaces. For example, the collaborative creation of content through discussion and iterative feedback in online spaces has been shown to play a significant role in the development of critical thinking in physiotherapy students (Rowe, Bozalek and Frantz 2013).

Unfortunately, the dominant use of technology in education has been to reinforce teaching methods that simply improve the efficiency of content delivery without any improvement in learning (Wilson et al 2008). If educators believe that the purpose of higher learning is to share information with students, then it follows that their use of technology will conform to that model of teaching. In this case the integration of technology in itself will have a limited impact on learning and will often simply reinforce passive, teachercentred, didactic teaching (Herrington et al 2009). However, if teaching practices are informed by appropriate pedagogy, then technology can be used to design novel, interactive learning activities that fundamentally change those practices (Veletsianos 2011). Whether physiotherapy educators are thinking about blogging (Tan, Ladyshewsky and Gardner 2010), wikis (Rowe 2012a), gaming (Kron, Gjerde, Sen, and Fetters 2010), Facebook (Garner and O'Sullivan 2010) or other social networks (Rowe 2012 b), there is an increasing body of literature that can be used to inform 
changes in physiotherapy education.

When exploring the use of technology as part of established teaching practices, physiotherapy educators should avoid thinking of the process as simply adding another task or activity to the programme. Consideration should be given to the systematic and thoughtful fusion of online and face-to-face activities that uses the strengths of each approach to support and enhance learning interactions between students, teachers and resources (Garrison and Kanuka 2004). It is more than the addition of a technological component to a traditional curriculum and should be seen as a "fundamental redesign that transforms the structure of, and approach to, teaching and learning" (Garrison and Vaughan 2008). Physiotherapy educators must recognise that each learner has different needs and that learning is a continuous process that is difficult to constrain within the physical and temporal limitations of the curriculum. Integrating technology effectively enables students to engage in a range of situations and time frames with more flexibility according to their individual circumstances (Aspden and Helm 2004). In order to make effective use of digital technology in the physiotherapy curriculum, we must look beyond the superficial addition of computer-based activities to the programme and ensure that the use of technology is driven by the aim of enhancing communication and authentic discussion between teachers and students.

Rather than simply providing students with information, the teacher now has a more critical role as someone who is not only a mediator of articulated knowledge, but who is also deeply involved in scaffolding the thinking and learning processes of students (Laurillard 2012). Integrating technology into the learning environment has the potential to shape what is being learned by changing how it is being learned (Laurillard 2012). By engaging in shared learning experiences that extend beyond the walls of the classroom, we may be able to provide learners with opportunities to develop the knowledge and mindsets necessary to "participate in complex, ever-shifting real world situations in which coming to know is as important as knowing" (Cormier and Siemens 2010 p. 38). The role of the physiotherapy educator is therefore to structure the learning experience so that the student is guided towards deeper levels of understanding, particularly around integrating classroom and clinical experiences (Rowe 2012b).

\section{CHALLENGES WITH INTEGRATING TECHNOLOGY}

However, there are significant challenges inherent in a process of integrating technology into teaching and learning practices, especially in South Africa (Moll et al 2007). We have noted that access to technology in itself has a limited impact on learning outcomes, often merely reinforcing ineffective teaching methods (Herrington et al 2007). There is also evidence of a lack of understanding among some physiotherapy students about how online services can be used as part of their learning practices, even when they are familiar with those services as part of their social practices (Rowe et al 2012). This would suggest that before implementing a technology-integrated approach in the classroom, physiotherapy educators should not only pay particular attention to the pedagogical objectives they want to achieve, but should also ensure that students are well-prepared for the activity.

In addition, some students have reported difficulty adjusting to the structure of online courses and managing their time in such environments (Marino 2000). In online activities, the physical absence of the instructor and the increased responsibility on learners may present individual challenges, particularly among those with low selfregulatory skills (Dabbagh and Kitsantas 2005). It should be noted that novice learners are less self-regulated and need frequent direction and reinforcement from a facilitator and may subsequently feel frustrated in purely online courses. These frustrations could be eased if the online activities are combined with periodic opportunities for face-to-face interactions (Rovai and Jordan 2004).

\section{CONCLUSION}

Clinical reasoning is a complex process, made more difficult by the fact that it is tacit and hidden from the novice practitioner. The careful integration of technology into the classroom environment can provide authentic learning spaces that help induct students into the professional culture and ways of thinking that could improve their development of practice knowledge. This is especially true when educators are themselves embedded within the process and are not seen simply as the providers of information. Therefore, the aim of the physiotherapy educator must be to use technology to facilitate enhanced communication and interaction between themselves and students, rather than simply to improve the efficiency of content delivery. We believe that physiotherapy education must move away from simply serving students with content, and that classroom spaces must be seen as environments for active discussion and debate, facilitated by the use of technology as part of appropriate pedagogical design.

\section{REFERENCES}

Aspden L, Helm P. 2004. Making the Connection in a Blended Learning. Environmental and Educational Media International. 41: 245-52.

Cohen JC. 2004. Instituting improvement in medical education. Reporter 13(11):2 (publication of the AAMC).

Cormier D, Siemens G. 2010. The open course. Through the open door: Open courses as research, learning, and engagement. Educause Review, July / August, 31-39.

Dabbagh N, Kitsantas A. 2005. The role of Web-based pedagogical tools in supporting student self-regulation in distributed learning environments. Instructional Science. 25: 24-37.

Fraser SW, Greenhalgh T. 2001. Coping with complexity: Educating for capability. British Medical Journal. 2001. 323: 799-803.

Garner J, O'Sullivan H. 2010. Facebook and the professional behaviours of undergraduate medical students. Clinical Teacher, 7(2), 112-5.

Garrison R, Kanuka, H. 2004. Blended learning: Uncovering its transformative potential in higher education. The Internet and Higher Education, 7:95-105. 
Garrison DR, Vaughan ND. 2008. Blended learning in higher education: Framework, principles, and guidelines. San Francisco, CA: Jossey-Bass.

Graffam B. 2007. Active learning in medical education: strategies for beginning implementation. Medical Teacher, 29(1), 38-42.

Herrington, J. 2006. Authentic e-learning in higher education: Design principles for authentic learning environments and tasks. World Conference on E-learning in Corporate, Government, Healthcare and Higher Education.

Herrington J, Reeves TC, Oliver R. 2007. Immersive learning technologies: Realism and online authentic learning. Journal of Computing in Higher Education. 19: 80-99.

Herrington J, Herrington A, Mantei J, Olney I, Ferry B. 2009. New technologies, new pedagogies: Mobile learning in higher education. University of Wollongong. Available from http://ro.uow.edu. $\mathrm{au} /$ newtech/.

Higgs J, Richardson B, Dahlgren M. 2004. Developing Practice Knowledge for Health Professionals. Butterworth-Heinemann, London.

Kron FW, Gjerde CL, Sen A, Fetters MD. 2010. Medical student attitudes toward video games and related new media technologies in medical education. BMC medical education, 10, 50.

Laurillard D. 2002. Rethinking university teaching: A conversational framework for the effective use of learning technologies. London: Routledge Falmer.
Laurillard D. 2012. Teaching as a design science: Building pedagogical patterns for learning and technology. Routledge, Taylor and Francis Group, New York and London.

Lombardi MM, Oblinger DG. 2007. Authentic learning for the 21st century: An overview. EDUCAUSE learning initiative, May 2007.

Moll I, Adam F, Backhouse J, Mhlanga E. 2007. Status report on ICTs and higher education in South Africa. South African Institute for Distance Education

Rovai AP, Jordan HM. 2004. Blended learning and sense of community: A comparative analysis with traditional and fully on-line graduate courses The International Review of Research in Open and Distance Learning. 5(2), 1492-3831

Rowe M. 2012a. The use of a wiki to facilitate collaborative learning in a South African physiotherapy department. South African Journal of Physiotherapy, 68(2), 11-16.

Rowe M. 2012b. The use of assisted performance within an online social network to develop reflective reasoning in undergraduate physiotherapy students. Medical Teacher, 34(7), e469-75.

Rowe, M, Bozalek, V, Frantz, J. (2013). Using Google Drive to facilitate a blended approach to authentic learning. British Journal of Educational Technology, 44(4):594-606.

Rowe M, Frantz J, Bozalek V. 2012. Physiotherapy students' use of emerging online technology as part of their learning practices. South African Journal of Physiotherapy. 68:29-34.
Seely Brown J, Collins A, Duguid P. 1989. Situated cognition and the culture of learning. Educational Researcher, 18(1), 32-42.

Tan, SM, Ladyshewsky, RK, Gardner, P. 2010. Using blogging to promote clinical reasoning and metacognition in undergraduate physiotherapy fieldwork programs. Australasian Journal of Educational Technology, 26(3), 355-368.

Veletsianos G. 2011. Designing opportunities for transformation with emerging technologies. Educational Technology. 51: 41-6.

Vygotsky L. 1978. Mind In Society: The development of higher psychological processes. Cambridge, Harvard University Press. ISBN: 0674576292. 1978.

Wilson B, Parrish P, Veletsianos G. (2008). Raising the bar for instructional outcomes: Towards transformative learning experiences. Educational Technology, 48(3), 39-44. 